\title{
Non-detection of Chlamydia species in carotid atheroma using generic primers by nested PCR in a population with a high prevalence of Chlamydia pneumoniae antibody Grace M Ong ${ }^{* 1}$, Peter V Coyle ${ }^{1}$, Aires AB Barros D' $\mathrm{Sa}^{2}$, W Glenn McCluggage ${ }^{3}$, W Paul Duprex ${ }^{4}$, Hugh J O'Neill ${ }^{1}$, Dorothy E Wyatt ${ }^{1}$, Kathleen B Bamford ${ }^{5}$, Barney O'Loughlin ${ }^{6}$ and Conall McCaughey ${ }^{1}$
}

\begin{abstract}
Address: ${ }^{1}$ Regional Virus Laboratory, Royal Hospitals Trust, Grosvenor Road, Belfast, BT12 6BA, UK, ${ }^{2}$ Regional Vascular Unit, Royal Hospitals Trust, Grosvenor Road, Belfast, BT12 6BA, UK, ${ }^{3}$ Department of Pathology, Royal Hospitals Trust, Grosvenor Road, Belfast, BT12 6BA, UK, ${ }^{4}$ School of Biology and Biochemistry, The Queen's University of Belfast, Lisburn Road, Belfast, UK, ${ }^{5}$ Department of Infectious Diseases and Microbiology, Imperial College School of Medicine, Hammersmith Hospital Campus, London, UK and ${ }^{6}$ Department of Microbiology and Immunobiology, The Queen's University of Belfast, Royal Hospital Campus, Belfast BT12 6BN, UK

E-mail: Grace M Ong* - grace.ong@bll.n-i.nhs.uk; Peter V Coyle - peter.coyle@bll.n-i.nhs.uk; Aires AB Barros

D'Sa - Aires.barrosd'sa@ royalhospitals.n-i.nhs.uk; W Glenn McCluggage - Glenn.mccluggage@bll.n-i.nhs.uk;

W Paul Duprex - p.duprex@qub.ac.uk; Hugh J O'Neill - hugh.oneill@bll.n-i.nhs.uk; Dorothy E Wyatt - dorothy.wyatt@bll.n-i.nhs.uk; Kathleen B Bamford - k.bamford@ic.ac.uk; Barney O'Loughlin - b.oloughlin@qub.ac.uk; Conall McCaughey - conall.mccaughey@bll.ni.nhs.uk

*Corresponding author
\end{abstract}

Published: 24 August 200I

Received: I August 200 I

BMC Infectious Diseases 200I, I:12

Accepted: 24 August 2001

This article is available from: http://www.biomedcentral.com/I47/-2334/I//2

(c) 200 I Ong et al; licensee BioMed Central Ltd. Verbatim copying and redistribution of this article are permitted in any medium for any non-commercial purpose, provided this notice is preserved along with the article's original URL. For commercial use, contact info@biomedcentral.com

\begin{abstract}
Background: The association of Chlamydia pneumoniae with atherosclerosis is controversial. We investigated the presence of $C$. pneumoniae and other Chlamydia spp. in atheromatous carotid artery tissue.
\end{abstract}

Methods: Forty elective carotid endarterectomy patients were recruited (27 males, mean age 65 and 13 females mean age 68), 4 had bilateral carotid endarterectomies $(n=44$ endarterectomy specimens). Control specimens were taken from macroscopically normal carotid artery adjacent to the atheromatous lesions (internal controls), except in 8 cases where normal carotid arteries from post mortem (external controls) were used. Three case-control pairs were excluded when the HLA DRB gene failed to amplify from the DNA. Genus specific primers to the major outer membrane protein (MOMP) gene were used in a nested polymerase chain reaction ( $\mathrm{nPCR}$ ) in $4 \mathrm{I}$ atheromatous carotid specimens and paired controls. PCR inhibition was monitored by spiking with target $C$. trachomatis. Atheroma severity was graded histologically. Plasma samples were tested by microimmunofluorescence (MIF) for antibodies to $C$. pneumoniae, $C$. trachomatis and $C$. psittaci and the corresponding white cells were tested for Chlamydia spp. by nPCR.

Results: C. pneumoniae was not detected in any carotid specimen. Twenty-five of 38 (66\%) plasma specimens were positive for $C$. pneumoniae $\lg G, 2 / 38$ (5\%) for $C$. trachomatis $\lg G$ and $I / 38$ (3\%) for C. psittaci lgG.

Conclusions: We were unable to show an association between the presence of Chlamydia spp. and atheroma in carotid arteries in the presence of a high seroprevalence of $C$. pneumoniae antibodies in Northern Ireland. 


\section{Background}

C. pneumoniae is a respiratory pathogen causing community-acquired pneumonia, bronchitis, pharyngitis and sinusitis [1]. While an association between C. pneumoniae and atherosclerosis has been suggested, its exact role in the pathogenesis of atherosclerosis remains uncertain. Some, but not all, seroepidemiological studies [2],[3] have shown elevated antibody levels to C. pneumoniae in patients with coronary artery disease and many studies have also detected the presence of $C$. pneumoniae in atherosclerotic tissue [4],[5].However, others have either failed to detect the organism [6] or demonstrated a low prevalence in arterial tissues [7].

The fact that both C. psittaci and C. pneumoniae are respiratory pathogens and that the pathogenesis of C. pneumoniae and atherosclerosis may be analogous to the development of trachoma by C. trachomatis[8], would support the necessity to determine whether other Chlamydia spp. beside C. pneumoniae are present in arterial tissue. In this study we aimed to investigate the presence of Chlamydia spp. in carotid artery atheroma using genus specific chlamydia primers in a nested polymerase chain reaction (nPCR).

\section{Materials and Methods \\ Patients and specimens}

Specimens were collected from 40 patients enrolled for elective carotid endarterectomy between 1998 and 1999. Patients' ages ranged from 42 to 84 years and included 27 males (mean age 65) and 13 females (mean age 68). Four patients ( 2 males and 2 females) had bilateral carotid endarterectomies giving a total of 44 endarterectomy specimens. All specimens were graded macroscopically as follows: Grade o normal artery, Grade 1 fatty streak, Grade 2 fibrolipid plaque and Grade 3 advanced lesion with fibrosis, calcification, ulceration or haemorrhage [9].

For each specimen macroscopically normal artery adjacent to the atheromatous area, removed as part of the normal surgical procedure, was used as an internal control (36 specimens). Endarterectomy specimens which did not have macroscopically normal areas adjacent to the atheromatous section were age and sex matched with external controls taken from normal post-mortem carotid arteries (8 specimens) following consent from relatives of the deceased. The carotid arteries were collected immediately from theatre and divided into two main sections, atheromatous and non-atheromatous, using a sterile technique. Each section was further divided to obtain specimens for histology, which were stored in 10\% non-buffered formalin. Specimens not processed for histology were transferred to polypropylene tubes (Sarstedt Ltd., Leicester, England), snap-frozen in liquid nitrogen, and stored at $-70^{\circ} \mathrm{C}$ until processed. A $5 \mathrm{ml}$ blood sample was taken into ethylenediamine tetraacetic acid (EDTA) from each patient on admission.

\section{Polymerase chain reaction (PCR)}

Specimen processing

Preparation of carotid arteries DNA was extracted from 25-30 mg of the carotid tissue from each patient using the QIAamp Tissue Kit (Qiagen Ltd., Crawley, England).The extract was stored at $-70^{\circ} \mathrm{C}$ until tested.

Preparation of White Cells And Plasma. Whole blood in EDTA was spun in a plastic conical centrifuge tube (Nunc, Kamstrup, Denmark) at $330 \mathrm{~g}$ for 5 minutes and the plasma removed to a $1.8 \mathrm{ml}$ polypropylene tube (Sarstedt Ltd., Leicester, England). The cell pellet was made up to $10 \mathrm{ml}$ with red cell lysing buffer containing $0.15 \mathrm{M} \mathrm{NH}_{4} \mathrm{CL}$, $0.01 \mathrm{M} \mathrm{NaHCO}_{3}$ and $1 \mathrm{mM}$ EDTA (Sigma, Poole, England), left at room temperature for 15 minutes and spun at $330 \mathrm{~g}$ for 5 minutes. The supernatant was replaced with $10 \mathrm{ml}$ of PBS and the tube inverted gently 4 times. After a second spin at $330 \mathrm{~g}$ for 5 minutes the supernatant was removed and the cells counted in a Kova Glasstic 10 well grid (Hycor Biomedical Inc., California, USA) before making up to a final concentration of $1 \times 10^{7}$ cells $/ \mathrm{ml}$ in white cell lysing buffer constituted from $4 \mathrm{M}$ guanidinium isothiocyanate in $3 \mathrm{M}$ sodium acetate (Sigma, Poole, England) at pH 6.o. A volume of $200 \mu \mathrm{l}$ (equivalent to $2-10^{6}$ cells) was extracted using the QIAamp Blood Kit ((Qiagen Ltd., Crawley, England). White cells and plasma were stored at $-70^{\circ} \mathrm{C}$ until tested.

\section{Primers}

The primers used are shown together with the size of their respective $1^{\text {st }}$ and $2^{\text {nd }}$ round products (Table 1 ).

\section{Mastermixes for PCR}

The final $25 \mu$ l volume of the the $1^{\text {st }}$ round reaction mix for Chlamydia spp. nPCR contained $5 \mathrm{pmol}$ and $25 \mathrm{pmol}$ of the outer primers $\mathrm{CHL} 2 \mathrm{~A}$ and $\mathrm{CHL} 2 \mathrm{~B}$ respectively, 10 $\mathrm{mM}$ Tris-HCl pH 9.0, $3.5 \mathrm{mM} \mathrm{MgCl} 2,50 \mathrm{mM} \mathrm{KCl,} 0.2$ $\mathrm{mM}$ for each dNTP, $0.1 \%$ Triton $\mathrm{X}-100$ and 0.625 units of Taq enzyme. The final $25 \mu$ volume for HLADRB PCR mastermix contained $5 \mathrm{pmol}$ of each primer.

The final $25 \mu \mathrm{l}$ volume of the $2^{\text {nd }}$ round reaction mix for Chlamydia spp contained $10 \mathrm{pmol}$ and $25 \mathrm{pmol}$ of the inner primers $\mathrm{CHL} 2 \mathrm{C}$ and $\mathrm{CHL} 2 \mathrm{D}$ respectively, $10 \mathrm{mM}$ Tris-HCl pH 9.0, 3.5 mM MgCl2, $50 \mathrm{mM} \mathrm{KCl,} 0.2 \mathrm{mM}$ for each dNTP, $0.1 \%$ Triton X-100 and 0.625 units of Taq enzyme.

Extracted specimens $(5 \mu \mathrm{l})$ were added to $20 \mu \mathrm{l}$ of the first round mix and subjected to the $1^{\text {st }}$ round cycling 
Table I: Primers for Chlamydia spp. (CHL2A-2D) and HLADRB gene (Amp A, Amp B).

\begin{tabular}{lll}
\hline Primer & Sequence & Specificity \\
\hline CHL2A & 5'-GAA AAA ACT CTT RAA RTC GG-3' & MOMP gene 180/183 bp \\
CHL2B & 5'-CGN ANG CTW ATR GCR TCR CAC CAA G-3' & MOMP gene I80/183 bp \\
CHL2C & 5'-TGC CTG TRG GGA AYC CWK CTG AWC CAA G-3' & MOMP gene 94 bp \\
CHL2D & 5'-CAA GTN CNR CAA GGA TCR CAA GGA TC-3' & MOMP gene 94 bP \\
AMPA & 5'-CCC CAC AGC ACG TTT CYT G-3' & HLADRB gene 274 bP \\
AMPB & 5'-CCG CTG CAC TGT GAA GCT CT-3' & I HLADRB gene 274 bP \\
\end{tabular}

Primers $A \& B$ were outer primers and $C \& D$ were inner primers.

conditions. A $0.5 \mu \mathrm{l}$ volume of the reaction product from the first round was transferred to $24.5 \mu \mathrm{l}$ of second round mix for the 2nd round.

\section{Cycling conditions}

Hot-start PCR was carried out in a Perkin Elmer GeneAmp 2400 thermal cycler. Cycling conditions are given in Tables 2,3.

Table 2: PCR Cycling Conditions: Chlamydia genus specific

\begin{tabular}{lll}
\hline Cycle Conditions & First Round & Second Round \\
\hline PrePCRdenaturation & $94^{\circ} \mathrm{C}-3$ min & $94^{\circ} \mathrm{C}-2$ min \\
Denaturation & $94^{\circ} \mathrm{C}-10 \mathrm{~s}$ & $94^{\circ} \mathrm{C}-10 \mathrm{~s}$ \\
Annealing & $45^{\circ} \mathrm{C}-10 \mathrm{~s}$ & $45^{\circ} \mathrm{C}-10 \mathrm{~s}$ \\
Extension & $72^{\circ} \mathrm{C}-30 \mathrm{~s}$ & $72^{\circ} \mathrm{C}-30 \mathrm{~s}$ \\
Number of Cycles & 35 & 35 \\
& & \\
\hline
\end{tabular}

First and second round products were visualised together on ethidium bromide-stained $2 \%$ agarose gels and photographed (Polaroid). Specimens were regarded as positive if an appropriately sized band was present on $1^{\text {st }}$ and/or $2^{\text {nd }}$ round PCR. C. trachomatis, C. pneumoniae and NFW controls were included in each round for the respective PCR.

Table 3: PCR Cycling Conditions: HLA DRB gene

\begin{tabular}{ll}
\hline Cycle Conditions & First Round \\
\hline & \\
PrePCRdenaturation & $96^{\circ} \mathrm{C}-5 \mathrm{~min}$ \\
Denaturation & $96^{\circ} \mathrm{C}-1 \mathrm{~min}$ \\
Annealing & $55^{\circ} \mathrm{C}-1 \mathrm{~min}$ \\
Extension & $72^{\circ} \mathrm{C}-1 \mathrm{~min}$ \\
Number of Cycles & 40
\end{tabular}

\section{Assay Sensitivity}

Stocks of C. trachomatis and C. pneumoniae of known $\mathrm{TCID}_{50}$ were used to determine the detection endpoints for the first and second round of the generic nPCR. The $1^{\text {st }}$ and $2^{\text {nd }}$ round endpoints were $10^{-4}$ and $10^{-7}$ for C. trachomatis and $10^{-3}$ and $10^{-6}$ for $C$. pneumoniae equating to 1 and $0.001 \mathrm{TCID}_{50}$ respectively.

Determination of $T C I D_{50}$ for $C$. trachomatis and $C$. pneumoniae Shell vials were seeded with McCoy cells grown in McCoy growth medium (MEM Eagles, inactivated fetal calf serum, glutamine, non essential amino acids, gentamicin) and incubated for $24 \mathrm{hrs}$ at $37^{\circ} \mathrm{C}$ in a $10 \% \mathrm{CO}_{2}$ environment. Logarithmic dilutions of $500 \mu \mathrm{l}$ of $C$. trachomatis cell culture controls from $10^{-3}$ to $10^{-7}$ were added to the shell vials in rows of 4 for each dilution. After centrifugation at $2000 \mathrm{rpm}$ for 1 hour at room temperature the vials were incubated for 48 hours at $34^{\circ} \mathrm{C}$ in a $10 \% \mathrm{CO}_{2}$ environment. After 48 hours each shell vial was washed with PBS and fixed in methanol. $150 \mu \mathrm{l}$ of a 1:5 dilution of anti-chlamydia direct mmunofluorescence reagent (Dako) was added to each shell vial and incubated for 1 hour at $37^{\circ} \mathrm{C}$. Following a further wash with PBS the vials were examined for elementary bodies under the immunofluorescence microscope. $C$. pneumoniae was grown in Hep2 cells using the same protocol and growth medium as described above. Logarithmic dilutions of $500 \mu \mathrm{l}$ of $C$. pneumoniae cell culture controls from $10^{-2}$ to $10^{-5}$ were added to the shell vials in rows of 4 for each dilution. For both organisms 1 TCID50 was calculated using the Karber formula.

\section{PCR of specimens}

All carotid specimens and white cells were tested using generic chlamydia nPCR. Aliquots of extracted DNA from all carotid specimens were spiked with C. trachomatis DNA at a weak dilution of $10^{-6}\left(0.01 \mathrm{TCID}_{50}\right)$ and retested using the generic chlamydia nPCR to monitor for PCR inhibition. PCR for HLADR-B gene was amplified in all carotid specimens to ensure adequate DNA was ex- 
tracted. Only carotid specimens from which the HLADRB gene was amplified were included in the study and tested withchlamydia nPCR.

\section{Serology}

The MRL Diagnostics Chlamydia MIF (micro-immunofluorescence) assay [10] was used to detect the presence of $\mathrm{IgG}$ antibodies to antigens from $C$. pneumoniae (TW183), C. psittaci (strains 6BC and DD34) and C. trachomatis (sero-types $\mathrm{D}-\mathrm{K}$ ) at a serum dilution of $1 / 16$. Slides were viewed at a magnification of 400 on a Leitz fluorescence microscope within 24 hours by two independent observers. Results were graded on a rank scale $\mathrm{O}, 1+, 2+, 3^{+}$and $4+$.

\section{Histology}

Carotid specimens fixed in 10\% formalin and embedded in paraffin wax were sectioned and stained with Haematoxylin \& Eosin. Specimens were graded histologically as follows on microscopic examination by 2 investigators: Grade o normal artery, Grade 1 intimal thickening, smooth muscle cell damage, macrophage and foam cell infiltration, Grade 2 central necrotic area with overlying fibrosis, cholesterol clefts and Grade 3 dense fibrosis, calcification, ulceration, neovascularisation or haemorrhage [9]

\section{Results}

\section{Patients and Specimens}

Three of the 44 cases and their paired controls were excluded when the HLA DRB gene failed to be amplified from the atheromatous carotid specimens. Patient characteristics are summarized in Table 4 .

Table 4: Characteristics of patients with carotid artery disease that underwent carotid endarterectomy and were enrolled in the study.

\begin{tabular}{ll}
\hline Characteristic & No.(\%) of patients \\
\hline & \\
Men & $25(66)$ \\
Women & $13(34)$ \\
Hypercholesterolaemia & $21(55)$ \\
Hypertension & $11(29)$ \\
Diabetes mellitus & $1(3)$ \\
Family history of CVA $/$ MI $^{\phi} /$ PVD $^{\#}$ & $16(42)$ \\
Smoker & $6(16)$ \\
Ex-smoker & $20(53)$ \\
Previous CVA/MI & $19(50)$ \\
& \\
\hline
\end{tabular}

${ }^{*} \mathrm{CVA}=$ cerebrovascular accident, ${ }^{\phi} \mathrm{Ml}=$ myocardial infarction, ${ }^{\#} \mathrm{PVD}$ = peripheral vascular disease

\section{PCR of specimens}

Chlamydia spp. were not detected in any carotid atheroma specimens. All the white cell specimens were negative for Chlamydia spp. Inhibition of the generic nPCR was not demonstrated in any carotid specimen when each aliquot was spiked with target $C$. trachomatis at a weak dilution of $10^{-6}$.

\section{Serology}

Twenty-five out of 38 (66\%) plasma specimens were positive for C. pneumoniae IgG. Two patients who had antibodies to $C$. pneumoniae were also positive for $C$. trachomatis $\operatorname{IgG}$ and one for C. psittaci $\operatorname{IgG}$.

\section{Histology}

Apart from the first three carotid specimens from patients and four post mortem control specimens, all specimens were fixed in formalin for retrospective confirmatory histological grading following macroscopic grading. Of the 41 control specimens that were grade 0 macroscopically, 11/41 (27\%) were grade 1 and 2/41 (5\%) were grade 2 on histological examination. Thirty disease specimens were grade 3 macroscopically of which 26 were also grade 3 and 1 was grade 2 on histology. The first 3 specimens were not examined histologically. Nine of 10 specimens of grade 2 on gross examination were confirmed as grade 2 and 1 as grade 1 on histology. One specimen was grade 1 on both macroscopic and microscopic examination.

\section{Discussion}

The number of specimens analyzed in this study was relatively small therefore the null finding could be due to chance. Previous meta-analysis showed the occurrence of $C$. pneumoniae in atheromatous lesions compared to non-atheromatous vessels of controls was $59 \%$ versus $3.1 \%[8]$. In our study Chlamydia spp. were not detected in any of the atheromatous carotid specimens which is the same as detection rates in a study of abdominal aortic aneurysms carried out by Lindholt et al[11]. Weiss et al only detected $C$. pneumoniae in one coronary atheroma [6]. C. pneumoniae was only detected in 4/50 (8\%) coronary atherectomies from patients in Germany [7].

Several measures were taken to ensure that our results were not false negatives. The sensitivity of the nPCR was determined by comparing the endpoints with titrations of C. trachomatis and C. pneumoniae of knownTCID ${ }_{50}$. The nested approach gave a $10^{3}$ increase in sensitivity. This was to ensure that the lack of detection of Chlamydia spp. was not due to lack of sensitivity of the nPCR. We looked for the presence of inhibitors in the tissue specimens. An aliquot of each extracted DNA specimen was spiked with a weak dilution of $C$. trachomatis DNA and amplified by PCR to exclude such inhibitors. We did 
not demonstrate any inhibition to our assay. In retrospect it would have been useful to spike the tissue sample with whole chlamydia particles prior to extraction to determine whether chlamydia DNA was being lost at the extraction step. Further studies should look at this aspect.

The size of specimens and method of DNA tissue extraction may account for the differences in the rate of detection. The heterogeneity of distribution of the organism within the tissue may elude detection by various methods as noted by Jackson et al [4]. Jantos et al [7] who used a different method and Paterson et al [12] who looked at larger samples of carotid endarterectomy and carotid and coronary arteries from autopsy also failed to detect C. pneumoniae . In this study the Qiagen tissue DNA kit, which is specific for DNA extraction from tissue samples, was used. The cumulative tissue analyzed in this study argues against the negative findings resulting from inadequate amounts of tissue investigated. In order to ensure that adequate DNA was extracted in this study, the HLADRB gene was amplified in each specimen. Results of chlamydia PCR in each individual specimen were only considered valid when the HLADRB gene was successfully amplified and when inhibition to the PCR was excluded. Care was also taken at all stages to avoid contamination of specimens, especially at the stage of DNA tissue extraction.

The difficulty of obtaining adequate numbers of diseasefree and age and sex matched controls has been a problem in previous investigations, especially in an elderly population. Taylor-Robinson suggested the best control comprises disease-free specimens adjacent to abnormal areas in vessels from the same subjects [8]. One study showed that $C$. pneumoniae was not detected by electron microscopy in adjacent tissue without disease [5]. In our study external controls from 8 age and sex matched post mortem patients were used when we were not able to identify adjacent tissue free of atheroma on macroscopic examination in patient specimens. Although 13/41 (32\%) of the controls were found retrospectively on histology to have signs of early atheroma development, Chlamydia spp. were not detected. There is much evidence from many workers that $C$. pneumoniae is present in atheromatous material including studies using electronmicroscopy, antigen detection and even culture.[13] However sensitive techniques such as PCR should be the gold standard for detection of organisms at low levels in atheromatous material. The wide range in detection rates in the literature is therefore surprising.

Apfalter et al have recently published a multicenter comparison trial of DNA extraction methods and PCR assays for detection of C. pneumoniae in endarterectomy speci- mens.[14] Despite this study an explanation for the wide discrepancies is unclear. In the Apfalter et al. study, the majority of methods (10/16) found all 15 specimens negative. Hence the majority consensus among the expert laboratories was that all the specimens were negative. Three methods were able to detect the low positive control (0.01 inclusions). Of these 3 most sensitive methods $2 / 3$ found all 15 specimens negative. In contrast, of the 2 laboratories that detected $C$. pneumoniae in the most clinical specimens, one does not detect the lowest positive control. This less sensitive laboratory/method (A) was the one that had the most positive results (9/15).

Unfortunately the study design employed by Apfalter et al. was not ideal for assessing specificity as only one negative control was employed. Suspiciously, the two laboratories that detect the most positives share a common extraction methodology (Boehringer High Pure PCR template preparation kit). This is a relatively intricate method with 6 spin steps. The consequent increase in manipulation steps over that associated with other extraction methods makes this method inherently potentially prone to amplicon and carry-over contamination. Working in a routine clinical laboratory, we avoid such potentially non-robust methods because of the potential associated specificity problems. The positive control data (samples C1-4) do not suggest that the Boehringer High Pure PCR template preparation kit confers a higher sensitivity as 2 methods not using this kit had better sensitivity than method $\mathrm{A}$, and a further 7 labs had equivalent sensitivity to method A. The two 'best' laboratories yield 9/15 (lab A) and 5/15 (lab B) positive results. The concordance between these two laboratories is not accessible from the data presented in the paper. We are not told if the $5 / 15$ positives in lab $B$ are included in the $9 / 15$ positives in lab $\mathrm{A}$. In addition the positive PCR products were not sequenced. Thus there was no attempt to show if the positive products represent real positive samples or are related to amplicon or carry-over contamination from laboratory or control samples. PCR contamination is an insidious problem. PCR contamination remains a viable explanation for the constellation of results presented by Apfalter et al. It is possible that the literature in this area is biased by false positive PCR results.

This work in the current study was carried out in a diagnostic laboratory (Regional Virus Laboratory, Belfast). We routinely use nested PCR assays as diagnostic procedures. In this setting we necessarily place much emphasis on specificity, including robust extraction methodologies and minimization of potential for contamination.

A publication bias against negative findings in well-conducted studies is something to be guarded against as it 
compromises future systematic review. We feel that this may be a particular problem in this subject area. We feel that there is a particular role for electronic journals such as BMC in which space, in contrast to paper journals, is not a limitation. Unlimited publication space will increase the chance that papers with negative findings are published.

Chlamydia spp. were not detected in carotid atheroma in this group of patients despite a high prevalence of $C$. pneumoniae antibodies comparable to that previously reported in the Northern Ireland population [15], an area with a high prevalence of atherosclerotic disease. Weiss et al who only detected the organism in one coronary atheroma by PCR also found that seroprevalence for $C$. pneumoniae antibodies did not correlate with the presence of $C$. pneumoniae in coronary atheroma in the patients in his study [6]. This implies that if there is any causal association between $C$. pneumoniae and atherogenesis then it must be indirect or that it is a variable that is not essential for atheroma development.

\section{Conclusion}

In this study we were not able to detect the presence of Chlamydia spp. in atheromatous specimensusing nPCR. Hence we are not able to support the direct involvement of chlamydia in the atherogenesis of carotid disease. Even if $C$. pneumoniae is present in atheromatous material it does not indicate that there is a causal association of infection with the organism and atherosclerosis. Other factors such as alteration of lipid profile [16], cytokine mediated endothelial injury $[17,18]$ molecular mimicry [19] or immune cross reactivity [20] may be an explanation for an indirect relationship of $C$. pneumoniae with atherogenesis considering the high prevalence of $C$. pneumoniae antibodies in this population.

\section{Competing interests}

None declared.

\section{References}

I. Grayston JT, Campbell LA, Kuo CC, Mordhorst CH, Saikku P, Thom $\mathrm{DH}$, et al: A new respiratory tract pathogen: Chlamydia pneumoniae strain TWAR. J Infect Dis 1990, 161:618-625

2. Saikku P, Leinonen M, Mattila K, Ekman MR, Nieminen MS, Makela PH, et al: Serological evidence of an association of a novel Chlamydia, TWAR, with chronic coronary heart disease and acute myocardial infarction. Lancet 1988, 2:983-986

3. Mendall MA, Carrington D, Strachan D, Patel P, Molineaux N, Levi J, et al: Chlamydia pneumoniae: risk factors for seropositivity and association with coronary heart disease. J Infect 1995, 30:121-128

4. Jackson LA, Campbell LA, Kuo CC, Rodriguez DI, Lee A, Grayston JT: Isolation of Chlamydia pneumoniae from a carotid endarterectomy specimen. J Infect Dis 1997, 176:292-295

5. Kuo CC, Shor A, Campbell LA, Fukushi H, Patton DL, Grayston JT: Demonstration of Chlamydia pneumoniae in atherosclerotic lesions of coronary arteries. J Infect Dis 1993, 167:84 I-849

6. Weiss SM, Roblin PM, Gaydos CA, Cummings P, Patton DL, Schulhoff $\mathrm{N}$, et al: Failure to detect Chlamydia pneumoniae in coronary atheromas of patients undergoing atherectomy [see comments]. J Infect Dis 1996, 173:957-962

7. Jantos CA, Nesseler A, Waas W, Baumgartner W, Tillmanns H, Haberbosch W: Low prevalence of Chlamydia pneumoniae in atherectomy specimens from patients with coronary heart disease [see comments]. Clin Infect Dis 1999, 28:988-992

8. Taylor-Robinson D, Thomas BJ: Chlamydia pneumoniae in arteries: the facts, their interpretation, and future studies [see comments]. J Clin Pathol 1998, 5 I:793-797

9. Ong G, Thomas BJ, Mansfield AO, Davidson BR, Taylor-Robinson D: Detection and widespread distribution of Chlamydia pneumoniae in the vascular system and its possible implications. J Clin Pathol 1996, 49:102-106

10. Freidank HM, Vogele H, Eckert K: Evaluation of a new commercial microimmunofluorescence test for detection of antibodies to Chlamydia pneumoniae, Chlamydia trachomatis, and Chlamydia psittaci. Eur J Clin Microbiol Infect Dis 1997, 16:685-688

II. Lindholt JS, Ostergard L, Henneberg EW, Fasting H, Andersen P: Failure to demonstrate Chlamydia pneumoniae in symptomatic abdominal aortic aneurysms by a nested polymerase chain reaction (PCR). Eur J Vasc Endovasc Surg 1998, 15:161-164

12. Paterson DL, Hall J, Rasmussen SJ, Timms P: Failure to detect Chlamydia pneumoniae in atherosclerotic plaques of Australian patients. Pathology 1998, 30:169-172

13. Apfalter P, Loidl M, Nadrchal R, Makristathis A, Rotter M, Bergmann $M$, et al: Isolation and continuous growth of Chlamydia pneumoniae from arterectomy specimens. Eur J Clin Microbiol Infect Dis 2000, 19:305-308

14. Apfalter P, Blasi F, Boman J, Gaydos CA, Kundi M, Maass M, et al: Multicenter comparison trial of DNA extraction methods and PCR assays for detection of Chlamydia pneumoniae in endarterectomy specimens. J Clin Microbiol 200I, 39:519-524

15. O'Neill C, Murray LI, Ong GM, O'Reilly DP, Evans AE, Bamford KB: Epidemiology of Chlamydia pneumoniae infection in a randomly selected population in a developed country. Epidemiol Infect 1999, I 22: I II-II6

16. Murray LJ, O'Reilly DP, Ong GM, O'Neill C, Evans AE, Bamford KB: Chlamydia pneumoniae antibodies are associated with an atherogenic lipid profile. Heart 1999, 8 I :239-244

17. Libby $\mathrm{P}, \mathrm{Galis} \mathrm{ZS}$ : Cytokines regulate genes involved in atherogenesis. Ann N Y Acad Sci 1995, 748: 158-168

18. Patel P, Mendall MA, Carrington D, Strachan DP, Leatham E, Molineaux N, et al: Association of Helicobacter pylori and Chlamydia pneumoniae infections with coronary heart disease and cardiovascular risk factors [see comments] [published erratum appears in BMJ 1995 Oct 14;3 II(70II):985]. BMJ I995, 3| I:7||-7|4

19. Bachmaier K, Neu N, de la Maza LM, Pal S, Hessel A, Penninger JM: Chlamydia infections and heart disease linked through antigenic mimicry [see comments]. Science 1999, 283:1335-1339

20. Xu Q, Willeit J, Marosi M, Kleindienst R, Oberhollenzer F, Kiechl S, et al: Association of serum antibodies to heat-shock protein 65 with carotid atherosclerosis [see comments]. Lancet 1993, $341: 255-259$

\section{Pre-publication history}

The pre-publication history for this paper can be accessed here:

http://www.biomedcentral.com/content/backmatter/ 1471-2334-1-12-b1.pdf 